\title{
Sleep duration, risk of obesity, and parental perceptions of residential neighborhood environments in 6-9 years-old children
}

\author{
Aristides M. Machado-Rodrigues ${ }^{1,2}$ (i) ｜ Daniela Rodrigues ${ }^{1}\left([) \quad\right.$ Augusta Gama $^{1}$ | \\ Helena Nogueira ${ }^{1}$ (i) | Luís P. Mascarenhas ${ }^{3}$ | Cristina Padez
}

${ }^{1}$ Research Centre for Anthropology and Health, University of Coimbra, Coimbra, Portugal

${ }^{2}$ High School of Education, Ci\&DEI, Polytechnic Institute of Viseu, Viseu, Portugal

${ }^{3}$ UniCentro, Department of Physical Education, Midwestern Paraná State University, Curitiba, Brazil

\section{Correspondence}

Artisides M. Machado-Rodrigues PhD, Research Centre for Anthropology and Health, Faculdade de Ciências e Tecnologia, Universidade de Coimbra, Apartado 3046, 3001-401 Coimbra, Portugal.

Email: rodriguesari@hotmail.com

\section{Funding information}

Fundação para a Ciência e a Tecnologia, Grant/Award Number:

FCOMP-01-0124-FEDER-007483

\begin{abstract}
Objectives: The present study aimed to analyze the association between healthy sleep duration of children and the parental perception of the social/ built environment.

Methods: A cross-sectional study was done and a sample of 8273 children (4183 females) aged 6-9 years was observed. Height $(\mathrm{cm})$ and weight $(\mathrm{Kg})$ were measured, and the body mass index (BMI) was calculated. Participants were classified as normal weight or overweight/obese. Sleep habits, sedentary behaviors (i.e., TV viewing) and environmental variables were assessed by questionnaire. Logistic regressions were used, with adjustments for age, sex, BMI, and sedentary time.

Results: Children whose parents reported a positive perception of the built environment in the residential area were 1.21 times more likely to have regular sleep habits during weekdays. Furthermore, children whose parents reported a negative perception of the social environment and safety were $81 \%$ more likely to have irregular sleep habits during the weekdays.

Conclusions: The present study revealed a positive association between regular sleep during the weekdays and the parental perception of the social/built environment (land use and urban design).
\end{abstract}

\section{1 | INTRODUCTION}

The scientific literature has consistently emphasized that irregular sleep habits in children impact a range of health problems such as impaired cognition (Astill, Van der Heijden, Van Ijzendoorn, \& Van Someren, Astill et al., 2012; Sampasa-Kanyinga et al., 2020; Xiao et al., 2020), behavioral difficulties (e.g., emotion regulation, aggression) (Kamphuis et al., 2012), and increased risks of overweight/obesity (Gazmararian \& Smith, 2020; Rosi et al., 2017). Because the prevalence of irregular sleep in children and adolescents has substantially increased in many countries during the past decades (Matricciani et al., 2012), prevention strategies strongly depend upon an understanding of its causes and correlates.

Across childhood, sleep duration patterns vary widely since they are driven by a complex interaction between biological processes, environmental, behavioral, and social factors (Bang et al., 2020; Busch et al., 2017). For example, among children of the primary school, sleep duration varies according to the school schedules, family routines, and cultural practices, among others. However, an issue of equal importance, that has received comparatively less attention, is the potential impact of the social and environmental factors in sleep duration of children. The overall patterns suggest that children from more 
disadvantaged circumstances have lower sleep quality and shorter duration than those from more advantaged backgrounds (Jarrin et al., 2014; Ordway et al., 2020).

On one hand, exposure to violence and crime and feeling unsafe in one's neighborhood has been associated with reductions in both quality and sleep duration of families (Hill et al., 2016; Simonelli et al., 2017). On the other hand, living in a neighborhood that is characterized by high levels of noise (e.g., from neighbors or highly trafficked streets) or high levels of artificial light (e.g., from street lamps) may directly undermine the initiation or maintenance of sleep (Fyhri \& Aasvang, 2010). This suggests that effects of residential neighborhood characteristics on sleep may represent one pathway by which neighborhood environment has an impact on health outcomes.

The majority of research on sleep habits, however, has been carried out on adults, with studies of children and adolescents often being based on small samples with homogeneous sociodemographic composition (Galland et al., 2012). Therefore, further research is needed on representative samples of children. The present study aimed to analyze the association between healthy sleep duration of Portuguese children and the parental perception of the social/built environment of their residential area.

\section{2 | MATERIALS AND METHODS}

\section{1 | Participants}

The Portuguese prevalence study of obesity in childhood (PPSOC) was a random cross-sectional survey conducted in mainland schools in Portugal between March 2009 and January 2010. Details on sampling and response rates can be found elsewhere (Machado-Rodrigues, Santana, Gama, Mourao, Nogueira, Rosado, \& Padez, 2014a). Sampling was based on a sex and age-specific proportionate stratified random design with district as the primary sampling unit. A total of 17509 2-13 years-old children were recruited among whom 8273 childrens (4183 females) aged 6-9 were included in the present analyses. Ethical approval for PPSOC was given by the Portuguese commission for data protection, which requires anonymity and nontransmissibility of data, corroborated by the Direção-Geral de Inovação e Desenvolvimento Curricular. Prior to data collection, informed written assent was obtained from parents or guardians.

\section{2 | Anthropometry}

Height and weight were measured by two trained technicians at school in the morning, using a portable Seca
217 standiometer and portable Seca 770 scales to the nearest $0.1 \mathrm{~cm}$ and $0.1 \mathrm{~kg}$, respectively, with participants in t-shirt and shorts. Body mass index (BMI, $\mathrm{kg} / \mathrm{m}^{2}$ ) was calculated and categorized using age and sex-adjusted cutoff points (Cole et al., 2000). The sample was divided into two weight-status groups, normal weight, and overweight/obese.

\section{3 | Sleep habits}

Sleep habits was assessed by questionnaires filled out by the parents, and information was recorded in terms of sleep duration. Thus, parents were asked to write down the usual bedtimes and wake times of their child on week days and at the weekend. Total sleep time was calculated in hours as the difference between bedtime and wake up time for weekdays and weekend days.

On the basis of the American academy of pediatrics recommendations to promote optimal health for 6-12 years children (American Academy of Pediatrics, 2016), sleep duration was classified as irregular if less than $9 \mathrm{~h}$ per night or higher than $12 \mathrm{~h}$ per night, and recommended/regular sleep if between 9 and $12 \mathrm{~h}$ per night; therefore, for the statistical analysis, sleep duration was dichotomized as healthy sleep (0) versus unhealthy sleep (1) duration. Similar procedure was used in other epidemiological studies of children (Machado-Rodrigues et al., 2018).

\section{4 | Environmental neighborhood perceptions}

Parental perceptions of their local neighborhoods were assessed by a questionnaire using the environmental module of the international physical activity prevalence study (IPS, 2002). This questionnaire has been previously used in Portuguese youth (Machado-Rodrigues, Santana, Gama, Mourao, Nogueira, Rosado, \& Padez, 2014b; Mota et al., 2005; Santos et al., 2009) showing good reliability (intra-class correlation coefficients ranging from 0.36 to 0.79) (Mota et al., 2005). The questionnaire was designed to be a brief assessment of variables believed to be related to the activity-friendliness of neighborhoods.

Subsequently, to reduce the 15 contextual variables into a more parsimonious and intelligible data without losing information, a categorical principal component analysis (CATPCA) was performed. CATPCA uses an optimal scaling approach that allows variables to be scaled at different levels and optimally quantified in the specific dimension (Nogueira et al., 2013). Four components satisfied this initial criterion, but only the first two had the premise of reliability, showing adequate internal 
consistency (Cronbach's alpha scores above 0.5) (Santos et al., 2009).

Two indices which explained about $54 \%$ of the original variance were used: (i) First index: Neighborhood built environment (land use and urban design): availability and proximity of infrastructure and facilities (retail, leisure and sports), access to destinations, physical feature availability, and maintenance of features, such as cycle paths and sidewalks, and general aesthetics (Cronbach's $\alpha=0.78$ ); (ii) Second index: Neighborhood social environment and safety: perceptions of disorder, crime, violence and safety, including road safety (Cronbach's $\alpha=0.63$ ). For the statistical analysis, indices were dichotomized based on a median split into negative overall perception versus positive overall perception.

\section{5 | Sedentary behavior}

Screen time was the indicator of SB and was based on TV viewing. The amount of time spent viewing TV was determined from the proxy-report instrument as in other epidemiological studies of children (Machado-Rodrigues et al., 2015; Machado-Rodrigues, Santana, Gama, Mourao, Nogueira, Rosado, Mota, et al., 2014a) and was expressed as $\mathrm{min} /$ day. Thus, parents reported their child's TV viewing habits during weekdays and at the weekend and a categorical variable was computed according to the recommendations of the AAP for children (AAP, 2016): less than $2 \mathrm{~h}$ per day and two or more hours per day. Similar procedure has been used in several epidemiological studies of children (Machado-Rodrigues et al., 2015; Machado-Rodrigues et al., 2017).

\section{$2.6 \quad$ Statistical analysis}

Means and $S D$ were calculated for all variables. Prior to analysis, the Kolmogorov-Smirnov test was conducted to check the normality of the distribution for indicators of body size and sleep duration on week days and at the weekend, and results indicated these measures were normality distributed. Sex-specific descriptive statistics were calculated for age, height, weight, BMI, and sleep duration on week days and at the weekend. One-way analysis of covariance (ANCOVA) was used to test the effect of sex and controlling for chronological age. All ANCOVAs were followed with Bonferroni-corrected post hoc tests.

Associations between sleep habits and the parental perception of the social/built environment of their residential area, controlling for potentially confounding effects of chronological age, sex, BMI, and time spent in sedentary behaviors (i.e., TV viewing), were estimated using logistic regression analysis. In the minimally adjusted model (Model 1), the social/built environment of their residential area was the sole predictor of the child regular sleep habits. Chronological age and sex were subsequently added as potential confounders (Model 2). In Model 3, BMI was added as a potential confounder. Finally, in the Model 4, the time spent sedentary (i.e., TV viewing) was also added as confounder. The complex samples generalized linear models procedure to produce results with robust standard errors that take into account clustering of participants by school were used. Significance was set at 5\%, and SPSS 15.0 (SPSS Inc., Chicago, Illinois, USA) was used.

\section{3 | RESULTS}

Characteristics of the sample stratified by sex are summarized in Table 1. The mean age of school children of this sample was $8.0( \pm 1.11)$ and $8.1( \pm 1.14)$ years for boys and girls, respectively. About $67.7 \%$ of girls were categorized as normal weight status, $23.1 \%$ as overweight, and $9.2 \%$ as obese; corresponding values for boys were $71.7 \%$, $19.7 \%$, and $8.9 \%$ for normal weight status, overweight and obese males, respectively. About $31 \%$ of boys and $29 \%$ of girls spent more than $2 \mathrm{~h}$ per day in front of TV. The mean values of the built environment index were 0.038 and -0.001 for boys and girls, respectively; corresponding values for the social environment and

TA B LE 1 Descriptive statistics of participants a and results of ANCOVAs (chronological age as co-variable) of the effect of sex on body size, sleep habits and TV-viewing

\begin{tabular}{|c|c|c|}
\hline Variable $^{a}$ & $\begin{array}{l}\text { Boys } \\
(n=4089)\end{array}$ & $\begin{array}{l}\text { Girls } \\
(n=4183)\end{array}$ \\
\hline Chronological age, years & $7.98(1.11)$ & $8.05(1.14)$ \\
\hline Weight (kg) & $29.3(7.4)$ & $29.2(7.5)^{b}$ \\
\hline Height (m) & $1.29(0.08)$ & $1.28(0.09)^{\mathrm{c}}$ \\
\hline BMI & $17.53(2.82)$ & $17.60(2.85)$ \\
\hline $\begin{array}{l}\text { Sleep habits (hours/day), week } \\
\text { days }\end{array}$ & $10.03(0.66)$ & $10.04(0.68)$ \\
\hline $\begin{array}{l}\text { Sleep habits (hours/day), } \\
\text { weekend days }\end{array}$ & $10.80(0.83)$ & $10.99(0.83)^{\mathrm{c}}$ \\
\hline $\begin{array}{l}\text { TV-viewing (hours/day), week } \\
\text { days }\end{array}$ & $1.33(0.51)$ & $1.30(0.48)^{\mathrm{c}}$ \\
\hline $\begin{array}{l}\text { TV-viewing (hours/day), } \\
\text { weekend days }\end{array}$ & $1.98(0.61)$ & $1.97(0.61)$ \\
\hline
\end{tabular}

${ }^{\mathrm{a}}$ Data are shown as mean $(S D)$ unless otherwise stated.

${ }^{\mathrm{b}} p<.05$.

${ }^{\mathrm{c}} p<.01$. 
safety index were -0.011 and 0.014 , respectively for males and females.

Weight and height were, on average, significantly higher in males, whereas sleep duration at the weekend was significantly higher in females than in males (i.e., girls: $11.0 \mathrm{~h}$ /day; boys: $10.8 \mathrm{~h}$ /day); furthermore, males spent significantly more time watching TV on week days than their female counterparts (i.e., girls: $1.30 \mathrm{~h}$ /day; boys: $1.33 \mathrm{~h}$ /day). Males and females did not significantly differ in BMI, sleep duration on week days, and TV-viewing at the weekend.

The associations between sleep habits with the built environment (land use and urban design) and the social environment, controlling for the afore-mentioned confounding effects are presented for week days and weekend in Table 2 and Table 3, respectively. For the week days, the crude model revealed a significant positive association between regular sleep habits and the parental positive perception of the social/built environment (land use and urban design) in the residential area. After controlling for the afore-mentioned confounders, children whose parents reported a positive perception of the built environment in the residential area were 1.21 times more likely to have regular sleep habits during weekdays than those children whose parents reported a negative perception of the built environment. Furthermore, after controlling for confounders, children whose parents reported a negative perception of the social environment were $81 \%$ more likely to have irregular sleep habits during the week days, than those children whose parents had a positive perception of the social environment and safety of their residential area.

Inspection of the final regression model, results revealed that children who are involved in more sedentary activities (i.e., TV viewing) during the week days were 2.21 times more likely to have irregular sleep habits than their peers who have healthy daily TV viewing habits (i.e., $<2 \mathrm{~h}$ /day); furthermore, findings also shown that

\begin{tabular}{|c|c|c|c|c|c|c|c|}
\hline & \multirow[b]{2}{*}{$n$} & \multirow[b]{2}{*}{ Model } & \multicolumn{5}{|c|}{ Sleep habits } \\
\hline & & & $\boldsymbol{B}$ & $\begin{array}{l}\text { Standard } \\
\text { Error }\end{array}$ & $e^{B}$ & 95\% C.I. & $p$ \\
\hline \multirow{4}{*}{$\begin{array}{l}\text { Built environment } \\
\text { (land use and urban } \\
\text { design) }\end{array}$} & \multirow[t]{4}{*}{8273} & 1 & 0.18 & 0.08 & 1.19 & $1.03-1.39$ & .02 \\
\hline & & 2 & 0.18 & 0.08 & 1.20 & $1.03-1.40$ & .02 \\
\hline & & 3 & 0.18 & 0.08 & 1.20 & $1.03-1.39$ & .02 \\
\hline & & 4 & 0.19 & 0.08 & 1.21 & $1.04-1.41$ & .02 \\
\hline \multirow{4}{*}{$\begin{array}{l}\text { Social environment } \\
\text { and safety }\end{array}$} & \multirow[t]{4}{*}{8273} & 1 & -0.26 & 0.08 & 0.77 & $0.66-0.90$ & .001 \\
\hline & & 2 & -0.25 & 0.08 & 0.78 & $0.67-0.91$ & .001 \\
\hline & & 3 & -0.24 & 0.08 & 0.79 & $0.68-0.92$ & .003 \\
\hline & & 4 & -0.21 & 0.08 & 0.81 & $0.70-0.95$ & .01 \\
\hline
\end{tabular}

Note: Model $1=$ unadjusted; Model $2=\operatorname{model} 1+$ sex and chronological age; Model $3=\operatorname{model} 2+$ BMI; Model $4=$ model $3+$ TV viewing.

\begin{tabular}{|c|c|c|c|c|c|c|c|}
\hline & \multirow[b]{2}{*}{$n$} & \multirow[b]{2}{*}{ Model } & \multicolumn{5}{|c|}{ Sleep habits } \\
\hline & & & B & S.E. & $e^{B}$ & 95\% C.I. & $p$ \\
\hline \multirow{4}{*}{$\begin{array}{l}\text { Built environment } \\
\text { (land use and urban } \\
\text { design) }\end{array}$} & \multirow[t]{4}{*}{8273} & 1 & 0.05 & 0.07 & 1.06 & $0.93-1.20$ & 0.42 \\
\hline & & 2 & 0.06 & 0.07 & 1.06 & $0.93-1.21$ & 0.36 \\
\hline & & 3 & 0.06 & 0.07 & 1.07 & $0.94-1.21$ & 0.34 \\
\hline & & 4 & 0.05 & 0.07 & 1.06 & $0.93-1.20$ & 0.42 \\
\hline \multirow{4}{*}{$\begin{array}{l}\text { Social environment and } \\
\text { safety }\end{array}$} & \multirow[t]{4}{*}{8273} & 1 & -0.002 & 0.07 & 1.00 & $0.88-1.14$ & 0.97 \\
\hline & & 2 & -0.01 & 0.07 & 0.99 & $0.87-1.13$ & 0.90 \\
\hline & & 3 & -0.01 & 0.07 & 0.99 & $0.87-1.13$ & 0.91 \\
\hline & & 4 & 0.02 & 0.07 & 0.98 & $0.88-1.14$ & 0.98 \\
\hline
\end{tabular}

Note: Model $1=$ unadjusted; Model $2=\operatorname{model} 1+$ sex and chronological age; Model $3=\operatorname{model} 2+$ BMI; Model $4=$ model $3+$ TV viewing.
T A B L E 2 The association between weekdays sleep habits with the parental perception of the built (land use and urban design) and social environment of their residential area

TA B LE 3 The association between weekend sleep habits with the parental perception of the built (land use and urban design) and social environment and safety of their residential area 
children who had irregular sleep habits were $96 \%$ more likely to be classified as overweight than their counterparts who had regular sleep habits (finding not displayed on tables).

On the other hand, findings for the weekend did not revealed any significant association between sleep habits of children and the parental perception of the social/built environment in their residential area.

\section{4 | DISCUSSION}

Simultaneous consideration of multiple built environmental and social features of the residential area of families and their impact on sleep duration of children is lacking. Findings of the present study revealed that children whose parents reported a positive perception of the built environment (land use and urban design) in the residential area were 1.21 times more likely to have regular sleep habits during weekdays. Similar trends were found in US children (Singh et al., 2010), highlighting the need of community strategies to provide environments with better conditions to avoid perpetuation of irregular sleep habits among children. Residential neighborhood characteristics could be a source of continuation of social inequalities in health and well-being through the reduction of sleep quality and their consequences in child health.

Several potential mechanisms may underlie the impact of the built environment on sleep duration of children. For example, the exposure to road-traffic and corresponding related noise (Christensen et al., 2016), air pollution and electric lighting (Knutson, 2014) may reduce sleep duration. Thus, the quite community, absence of air pollution, and even the balanced light exposure are each prominent features of the landscape, which, subsequently, may moderate the association between the positive perception of the built environment and the sleep duration of the Portuguese children of the present study.

On the other hand, a growing body of work indicates that experiences of neighborhood disadvantage place children at risk for poor sleep, and the present study revealed that children whose parents reported a negative perception of the social environment were $81 \%$ more likely to have irregular sleep habits during the week days. Those findings are consistent with previous studies examining the role of crime, violence, and neighborhood disadvantage (Billings et al., 2020; Singh \& Kenney, 2013). Recently, in the same line, parental perception of safety of their neighborhood/community was also associated with inadequate sleep of children (Hawkins \& Takeuchi, 2016; Ordway et al., 2020). Additionally, parental attitudes and beliefs towards sleep habits may be an additional factor that moderates the relationship between social features of the residential area and its impact on regular sleep of children.

Another source of variation, which could explain the different significant results from the week days to the weekend, is probably the effects of wake-time and bedtime during all week. Indeed, those shifts vary from week days to the weekend and it may result in weight problems. Findings of the present study have also shown that children who had irregular sleep habits were $96 \%$ more likely to be classified as overweight than their counterparts who had regular sleep habits on week days. Of note, this association was also reported in another study in Portuguese children (Padez et al., 2009), and similar trends were also found in a cross-sectional study of 5.159 children, revealing those who slept more during the weekend had lower risk of overweight and obesity (Wing et al., 2009). Furthermore, Wong and colleagues (Wong et al., 2013) reported that children slept $0.6 \mathrm{~h} /$ day longer $(p<.001)$ at the weekend days than on weekdays, corroborating results from the present study (i.e., males: $0.8 \mathrm{~h}$ /day; females: $0.9 \mathrm{~h} /$ day). The potential mechanism for this finding is likely to be at least partly behavioral. Indeed, obesogenic behaviors, such as TV watching and late-night snacking, are more common in the later evening. However, it is also possible that circadian phasedelay may play a role in explaining the risk for overweight/obesity, particularly given research suggesting the importance of circadian clocks in metabolism and obesity (Gazmararian \& Smith, 2020; Medic et al., 2017). Longitudinal studies, especially using objective instruments of sleep are needed to establish causality between sleep habits and overweight risk and obesity-related comorbidities in children.

The main strengths of the present study are the use of a large sample of 6-9 years-old Portuguese children and the simultaneous consideration of multiple built environment and social features of the residential area of their families. On the other hand, limitations of the present study should be also recognized; first, this study has a cross-sectional design and, therefore, it is not possible to infer casual relationships. Second, sleep habits, sedentary behaviors, and perceived neighborhood characteristics were obtained by self-reported instruments (e.g., parental proxy), which might be inaccurate and should be replaced by objective tools in the future researches.

\section{5 | CONCLUSION}

The present study revealed a significant positive association between regular sleep habits during the week days 
and the parental perception of the social/built environment in the residential area. These findings emphasize the need for policymakers to develop urban strategies to provide environments with better conditions to avoid irregular sleep duration, which could positively impact on health of our children.

\section{ACKNOWLEDGMENT}

This research was partially supported by Fundação para a Ciência e a Tecnologia [FCOMP-01-0124-FEDER007483].

\section{AUTHOR CONTRIBUTIONS}

Aristides Machado-Rodrigues: Conceptualization; data curation; formal analysis; investigation; methodology; writing - original draft; writing-review \& editing. Daniela Rodrigues: Data curation; investigation; methodology; project administration; writing - original draft; writing-review \& editing. Augusta Gama: Conceptualization; data curation; funding acquisition; investigation; writing - original draft; writing-review \& editing. Helena Nogueira: Conceptualization; data curation; investigation; methodology; resources; writing - original draft; writing-review \& editing. Luis Mascarenhas: Data curation; investigation; methodology; writing - original draft; writing-review \& editing. Conceptualization; data curation; funding acquisition; investigation; methodology; project administration; resources; validation; writing - original draft; writing-review \& editing.

\section{CONFLICTS OF INTEREST}

The authors report no conflicts of interest. The authors alone are responsible for the content and writing of the paper.

\section{DATA AVAILABILITY STATEMENT}

The data that support the findings of this study are available on request from the corresponding author. The data are not publicly available due to privacy or ethical restrictions.

\section{ORCID}

Aristides M. Machado-Rodrigues (1) https://orcid.org/00000002-7169-8034

Daniela Rodrigues (1) https://orcid.org/0000-0002-45594303

Helena Nogueira @ https://orcid.org/0000-0001-5724-3538

\section{REFERENCES}

American Academy of Pediatrics. (2016). Childhood Sleep Guidelines https://www.aap.org/en-us/about-the-aap/aap-press-ro om/pages/American-Academy-of-Pediatrics-Supports-ChildhoodSleep-Guidelines.aspx
Astill, R. G., Van der Heijden, K. B., Van Ijzendoorn, M. H., \& Van Someren, E. J. (2012). Sleep, cognition, and behavioral problems in school-age children: A century of research meta-analyzed. Psychological Bulletin, 138(6), 1109-1138. https://doi.org/ 10.1037/a0028204

Bang, F., Roberts, K. C., Chaput, J. P., Goldfield, G. S., \& Prince, S. A. (2020). Physical activity, screen time and sleep duration: Combined associations with psychosocial health among Canadian children and youth. Public Health Reports, 31(5), 9-16. https://doi.org/10.25318/82-003-x202000500002-eng

Billings, M. E., Hale, L., \& Johnson, D. A. (2020). Physical and social environment relationship with sleep health and disorders. Chest, 157(5), 1304-1312. https://doi.org/10.1016/j.chest. 2019.12.002

Busch, V., Altenburg, T. M., Harmsen, I. A., \& Chinapaw, M. J. (2017). Interventions that stimulate healthy sleep in schoolaged children: A systematic literature review. European Journal of Public Health, 27(1), 53-65. https://doi.org/10.1093/eurpub/ ckw140

Christensen, J. S., Hjortebjerg, D., Raaschou-Nielsen, O., Ketzel, M., Sorensen, T. I., \& Sorensen, M. (2016). Pregnancy and childhood exposure to residential traffic noise and overweight at 7years of age. Environment International, 94, 170-176. https:// doi.org/10.1016/j.envint.2016.05.016

Cole, T. J., Bellizzi, M. C., Flegal, K. M., \& Dietz, W. H. (2000). Establishing a standard definition for child overweight and obesity worldwide: International survey. BMJ, 320(7244), 1240-1243.

Fyhri, A., \& Aasvang, G. M. (2010). Noise, sleep and poor health: Modeling the relationship between road traffic noise and cardiovascular problems. Science of the Total Environment, 408(21), 4935-4942. https://doi.org/10.1016/j.scitotenv.2010.06.057

Galland, B. C., Taylor, B. J., Elder, D. E., \& Herbison, P. (2012). Normal sleep patterns in infants and children: A systematic review of observational studies. Sleep Medicine Reviews, 16(3), 213-222. https://doi.org/10.1016/j.smrv.2011.06.001

Gazmararian, J., \& Smith, J. (2020). Role of sleep duration and obesity-related health behaviors in young children. Preventive Medical Reports, 20, 101199. https://doi.org/10.1016/j.pmedr. 2020.101199

Hawkins, S. S., \& Takeuchi, D. T. (2016). Social determinants of inadequate sleep in US children and adolescents. Public Health, 138, 119-126. https://doi.org/10.1016/j.puhe.2016.03.036

Hill, T. D., Trinh, H. N., Wen, M., \& Hale, L. (2016). Perceived neighborhood safety and sleep quality: A global analysis of six countries. Sleep Medicine, 18, 56-60. https://doi.org/10.1016/j. sleep.2014.12.003

IPS. (2002). Physical activity prevalence study environmental survey module.

Jarrin, D. C., McGrath, J. J., \& Quon, E. C. (2014). Objective and subjective socioeconomic gradients exist for sleep in children and adolescents. Health Psychology, 33(3), 301-305. https://doi. org/10.1037/a0032924

Kamphuis, J., Meerlo, P., Koolhaas, J. M., \& Lancel, M. (2012). Poor sleep as a potential causal factor in aggression and violence. Sleep Medicine, 13(4), 327-334. https://doi.org/10.1016/j.sleep. 2011.12.006

Knutson, K. L. (2014). Sleep duration, quality, and timing and their associations with age in a community without electricity in 
Haiti. American Journal of Human Biology, 26(1), 80-86. https://doi.org/10.1002/ajhb.22481

Machado-Rodrigues, A. M., Fernandes, R., Gama, A., Mourao, I., Nogueira, H., Rosado-Marques, V., \& Padez, C. (2018). The association of irregular sleep habits with the risk of being overweight/obese in a sample of Portuguese children aged 6-9 years. American Journal of Human Biology, 30(4), e23126. https://doi.org/10.1002/ajhb.23126

Machado-Rodrigues, A. M., Leite, N., Coelho-e-Silva, M. J., Enes, F., Fernandes, R., Mascarenhas, L. P., ... Malina, R. M. (2015). Metabolic risk and television time in adolescent females. International Journal of Public Health, 60(2), 157-165. https://doi.org/10.1007/s00038-014-0625-Z

Machado-Rodrigues, A. M., Santana, A., Gama, A., Mourao, I., Nogueira, H., Rosado, V., ... Padez, C. (2014). Active commuting and its associations with blood pressure and adiposity markers in children. Preventive Medicine, 69, 132-134. https:// doi.org/10.1016/j.ypmed.2014.09.001

Machado-Rodrigues, A. M., Santana, A., Gama, A., Mourao, I., Nogueira, H., Rosado, V., \& Padez, C. (2014). Parental perceptions of neighborhood environments, BMI, and active behaviors in girls aged 7-9 years. American Journal of Human Biology, 26(5), 670-675. https://doi.org/10.1002/ajhb.22577

Machado-Rodrigues, A. M., Valente-Dos-Santos, J., Fernandes, R., Gama, A., Mourao, I., Nogueira, H., ... Padez, C. (2017). Waistto-height ratio and its association with TV viewing in a sample of Portuguese children aged 7-9years. American Journal of Human Biology, 29(5), 1-6. https://doi.org/10.1002/ajhb.23024

Matricciani, L., Olds, T., \& Petkov, J. (2012). In search of lost sleep: Secular trends in the sleep time of school-aged children and adolescents. Sleep Medicine Reviews, 16(3), 203-211. https://doi. org/10.1016/j.smrv.2011.03.005

Medic, G., Wille, M., \& Hemels, M. E. (2017). Short- and long-term health consequences of sleep disruption. Nature and Science of Sleep, 9, 151-161. https://doi.org/10.2147/NSS.S134864

Mota, J., Almeida, M., Santos, P., \& Ribeiro, J. C. (2005). Perceived neighborhood environments and physical activity in adolescents. Preventive Medicine, 41(5-6), 834-836. https://doi.org/10. 1016/j.ypmed.2005.07.012

Nogueira, H., Ferrao, M., Gama, A., Mourao, I., Rosado Marques, V., \& Padez, C. (2013). Perceptions of neighborhood environments and childhood obesity: Evidence of harmful gender inequities among Portuguese children. Health \& Place, 19, 69-73. https://doi.org/10.1016/j.healthplace.2012.10.005

Ordway, M. R., Sadler, L. S., Jeon, S., O'Connell, M., Banasiak, N., Fenick, A. M., ... Redeker, N. S. (2020). Sleep health in young children living with socioeconomic adversity. Research in Nursing \& Health, 43(4), 329-340. https://doi.org/10.1002/nur.22023

Padez, C., Mourao, I., Moreira, P., \& Rosado, V. (2009). Long sleep duration and childhood overweight/obesity and body fat. American Journal of Human Biology, 21(3), 371-376. https://doi.org/ 10.1002/ajhb.20884

Rosi, A., Calestani, M. V., Parrino, L., Milioli, G., Palla, L., Volta, E., ... Scazzina, F. (2017). Weight status is related with gender and sleep duration but not with dietary habits and physical activity in primary school Italian children. Nutrients, 9(6), 1-10. https://doi.org/10.3390/nu9060579

Sampasa-Kanyinga, H., Colman, I., Goldfield, G. S., Janssen, I., Wang, J., Podinic, I., ... Chaput, J. P. (2020). Combinations of physical activity, sedentary time, and sleep duration and their associations with depressive symptoms and other mental health problems in children and adolescents: A systematic review. International Journal of Behavioral Nutrition and Physical Activity, 17(1), 72. https://doi.org/10.1186/s12966-02000976-X

Santos, M. P., Page, A. S., Cooper, A. R., Ribeiro, J. C., \& Mota, J. (2009). Perceptions of the built environment in relation to physical activity in Portuguese adolescents. Health \& Place, 15(2), 548-552. https://doi.org/10.1016/j.healthplace.2008.08.006

Simonelli, G., Dudley, K. A., Weng, J., Gallo, L. C., Perreira, K., Shah, N. A., ... Patel, S. R. (2017). Neighborhood factors as predictors of poor sleep in the Sueno ancillary study of the Hispanic community health study/study of Latinos. Sleep, 40(1), 1-8. https://doi.org/10.1093/sleep/zsw025

Singh, G. K., \& Kenney, M. K. (2013). Rising prevalence and neighborhood, social, and behavioral determinants of sleep problems in US children and adolescents, 2003-2012. Sleep Disorders, 2013(1), 1-15. https://doi.org/10.1155/2013/394320

Singh, G. K., Siahpush, M., \& Kogan, M. D. (2010). Neighborhood socioeconomic conditions, built environments, and childhood obesity. Health Affairs (Millwood), 29(3), 503-512. https://doi. org/10.1377/hlthaff.2009.0730

Wing, Y. K., Li, S. X., Li, A. M., Zhang, J., \& Kong, A. P. (2009). The effect of weekend and holiday sleep compensation on childhood overweight and obesity. Pediatrics, 124(5), e994-e1000. https://doi.org/10.1542/peds.2008-3602

Wong, W. W., Ortiz, C. L., Lathan, D., Moore, L. A., Konzelmann, K. L., Adolph, A. L., ... Butte, N. F. (2013). Sleep duration of underserved minority children in a cross-sectional study. BMC Public Health, 13, 648. https://doi.org/10.1186/ 1471-2458-13-648

Xiao, Q., Chaput, J. P., Olds, T., Fogelholm, M., Hu, G., Lambert, E. V., ... Group, I. R. (2020). Sleep characteristics and health-related quality of life in 9- to 11-year-old children from 12 countries. Sleep Health, 6(1), 4-14. https://doi.org/10.1016/j. sleh.2019.09.006

How to cite this article: Machado-Rodrigues, A. M., Rodrigues, D., Gama, A., Nogueira, H., Mascarenhas, L. P., \& Padez, C. (2021). Sleep duration, risk of obesity, and parental perceptions of residential neighborhood environments in 69 years-old children. American Journal of Human Biology, e23668. https://doi.org/10.1002/ajhb.23668 